\title{
In vitro platelet aggregability studies: lack of evidence for platelet hyperactivity in systemic sclerosis
}

\author{
J E Price, P S Klimiuk, M I V Jayson
}

\begin{abstract}
Systemic sclerosis is characterised by vascular endothelial damage. Platelets adhering to the exposed subendothelium may contribute to the inflammatory changes found in the vessel wall. Increased in vitro platelet aggregability in systemic sclerosis has been reported. In vitro platelet aggregation of platelet rich plasma obtained from patients with systemic sclerosis (CREST (calcinosis, Raynaud's phenomenon oesophageal dysmotility, sclerodactyly, telangiectasia) variant) and from controls matched for age and sex was compared. Collagen, ADP, and platelet activating factor were used as aggregating agents. The actions of a platelet activating factor antagonist, BN52063, were also examined.

Each agonist caused dose dependent platelet aggregation; there was no difference in either rate of primary aggregation or maximum percentage aggregation between platelets derived from patients with systemic sclerosis and from the control group (analysis of variance). BN52063 was shown to be a dose dependent, competitive antagonist of platelet aggregation induced by platelet activating factor; there was no difference in its action on platelets derived from patients with systemic sclerosis or controls. These results do not support the hypothesis that platelets from patients with systemic sclerosis are hyperactive and may explain the disappointing results obtained with antiplatelet drugs in systemic sclerosis.
\end{abstract}

Systemic sclerosis is characterised by vascular endothelial damage. ${ }^{1}$ Endothelial damage in smaller arteries and arterioles leads to exposure of the subendothelium. Platelets adhering to the subendothelium may contribute to the inflammatory changes seen in the vessel wall by releasing inflammatory mediators. ${ }^{2}$

In vitro studies have suggested that platelets from patients with systemic sclerosis are hyperactive. ${ }^{3-6}$ If this is the case, thrombus formation at injured sites on vessel walls would be more extensive and platelets would be more likely to aggregate in the circulation on exposure to aggregating agents. Antiplatelet drugs may be clinically useful. Collagen is the basement membrane component responsible for platelet adherence, release, and aggregation. After adhesion to collagen the platelets release ADP. Platelet activating factor is a phospholipid considered to be an important inflammatory mediator, participating in many complex inflammatory and allergic disorders. It is a potent platelet aggregatory agent. We compared in vitro platelet aggregation in response to collagen, ADP, and platelet activating factor of platelet rich plasma obtained from patients with systemic sclerosis (CREST variant) and from controls matched for age and sex. The effects of BN50263, a specific platelet activating factor antagonist, on aggregation induced by platelet activating factor were also investigated.

\section{Patients and methods}

\section{PATIENTS}

Patients with systemic sclerosis (CREST variant) and normal controls matched for age and sex were selected for the study. Subjects more than $30 \%$ overweight as defined by Health Education Council guidelines ${ }^{7}$ were excluded.

All subjects were asked to avoid a fatty breakfast and to refrain from smoking on the day of the study. Blood sampling took place at 900 am using a 19 gauge needle and with minimal tourniquet and trauma.

PREPARATION OF PLATELET RICH AND PLATELET POOR PLASMA

To prepare platelet rich plasma $20 \mathrm{ml}$ blood was added to $3 \mathrm{ml}$ acid-citrate-dextrose $(34.7 \mathrm{mM}$ citric acid, $74.8 \mathrm{mM}$ trisodium citrate, 123.6 $\mathrm{mM}$ D-glucose-monohydrate, $\mathrm{pH} 4.8$ ) and centrifuged at $110 \mathrm{~g}$ for 20 minutes at room temperature. The top $75-85 \%$ platelet rich plasma was removed with a plastic pipette, avoiding contamination by red blood cells. Platelet count, mean platelet volume, and platelet distribution width were measured in whole blood and platelet rich plasma with a Coulter counter model S-plus-IV.

Platelet poor plasma was prepared by centrifuging whole blood anticoagulated with acidcitrate-dextrose at $2000 \mathrm{~g}$ for 10 minutes at room temperature.

PLATELET ACTIVATING FACTOR, ADP, AND COLLAGEN INDUCED PLATELET AGGREGATION Platelet aggregation studies using a Bio/Data Corporation aggregometer, model PAP4, were carried out within three hours of blood sampling. The platelet count in platelet rich plasma was adjusted to $250 \times 10^{9} / 1$ with autologous platelet poor plasma. Platelet activating factor (Sigma) $0 \cdot 1-500 \mu \mathrm{mol} / 1$ was prepared in Tyrodes buffer containing $0.38 \%$ bovine serum albumin. ADP (Sigma) 0.31-50 $\mu \mathrm{mol} / 1$ was prepared in TRIS-saline. Lyophilised soluble calf skin 
collagen (Bio/Data Corporation) was reconstituted with distilled water to a working concentration of $1.9 \mathrm{mg} / \mathrm{ml}$. Aliquots $(450 \mu \mathrm{l})$ of platelet rich plasma were incubated in the aggregometer at $37^{\circ} \mathrm{C}$ for three minutes before the addition of $50 \mu$ l platelet activating factor, ADP, or collagen. The aggregation profile was followed for at least five minutes. Lag phase, rate of primary aggregation (measured by slope at the steepest part of the curve), and maximum percentage aggregation were recorded.

EFFECT OF BN52063 ON AGGREGATION INDUCED BY PLATELET ACTIVATING FACTOR AND ADP BN52063 (Ipsen International) 10-1000 $\mu \mathrm{mol} / \mathrm{l}$ was prepared in $5 \%$ dimethyl sulphoxide in TRIS buffer. Aliquots $(400 \mu \mathrm{l})$ of platelet rich plasma were incubated at $37^{\circ} \mathrm{C}$ for three minutes in the aggregometer. BN52063 or 5\% dimethyl sulphoxide ( $50 \mu \mathrm{l}$ in each case) was added and the suspension was incubated for a further three minutes before the addition of $50 \mu \mathrm{l}$ platelet activating factor or ADP. The aggregation profile was allowed to develop for five minutes after addition of the aggregating agent. The rate of primary aggregation and maximum percentage aggregation were recorded.

\section{Results}

PREPARATION OF PLATELET RICH PLASMA

Blood samples were taken from 12 female patients with systemic sclerosis and 12 female control subjects. Table 1 gives details of the patients.

Platelet rich plasma was prepared with mean platelet yields of 80.6 (SD $7 \cdot 8) \%$ in the patient group and $90.0(10.2) \%$ in the control group.

The mean platelet volume (table 2) was significantly lower in platelet rich plasma than

Table 1 Details of 12 female patients with systemic sclerosis

\begin{tabular}{lllll}
\hline $\begin{array}{l}\text { Case } \\
\text { No }\end{array}$ & $\begin{array}{l}\text { Age } \\
\text { (years) }\end{array}$ & $\begin{array}{l}\text { Length of } \\
\text { history } \\
\text { (years) }\end{array}$ & $\begin{array}{l}\text { Clinical } \\
\text { features }\end{array}$ & $\begin{array}{l}\text { Anticentromere } \\
\text { antibody }\end{array}$ \\
\hline 1 & 54 & 6 & RST & + \\
2 & 58 & 18 & CRST & - \\
3 & 41 & 24 & RST & - \\
4 & 38 & 28 & CREST & + \\
5 & 47 & 28 & CRST & + \\
6 & 66 & 20 & CREST & + \\
7 & 40 & 8 & CRS & - \\
8 & 68 & 9 & CREST & + \\
9 & 40 & 30 & RES & + \\
10 & 56 & 42 & REST & - \\
11 & 66 & 14 & RST & + \\
12 & 69 & 10 & RES & - \\
\hline C=calcinosis; & R= Raynaud's & phenomenon; E=oesophageal
\end{tabular}

dysmotility; $S=$ =sclerodactyly; $T=$ telangiectasia

Table 2 Mean platelet volume in samples of whole blood and platelet rich plasma prepared from 12 patients with systemic sclerosis and from 12 control subjects. Results are expressed (in $f l$ ) as mean (SD)

\begin{tabular}{|c|c|c|}
\hline & \multicolumn{2}{|c|}{ Mean platelet volume (fl) } \\
\hline & $\begin{array}{l}\text { Whole } \\
\text { blood }\end{array}$ & $\begin{array}{l}\text { Platelet rich } \\
\text { plasma }\end{array}$ \\
\hline $\begin{array}{l}\text { Systemic sclerosis } \\
\text { Normal controls }\end{array}$ & $\begin{array}{l}7 \cdot 6(0 \cdot 8) \\
7 \cdot 5(0 \cdot 7)\end{array}$ & $\begin{array}{l}7 \cdot 3(0 \cdot 7)^{*} \\
7 \cdot 2(0 \cdot 7)^{*}\end{array}$ \\
\hline
\end{tabular}

Table 3 Platelet distribution width in samples of whole blood and platelet rich plasma prepared from 12 patients with systemic sclerosis and from 12 control subjects. Results are expressed (in arbitrary units) as mean (SD)

\begin{tabular}{lll}
\hline & \multicolumn{2}{l}{ Platelet distribution width (arb units) } \\
\cline { 2 - 3 } & $\begin{array}{l}\text { Whole } \\
\text { blood }\end{array}$ & $\begin{array}{l}\text { Platelet rich } \\
\text { plasma }\end{array}$ \\
\hline Systemic sclerosis & $17 \cdot 1(0 \cdot 5)$ & $17 \cdot 1(0 \cdot 5)$ NS \\
Normal controls & $17 \cdot 4(0 \cdot 6)$ & $16.9(0 \cdot 4)^{*}$
\end{tabular}

${ }^{*} \mathrm{p}<0.05$, Wilcoxon's signed rank test.

Table 4 Platelet counts in whole blood, platelet rich plasma, and adjusted platelet rich plasma prepared from 12 patients with systemic sclerosis and from 12 control subjects. Results are expressed (platelets $\left.\times 10^{9} / l\right)$ as mean $(S D)$

\begin{tabular}{llll}
\hline & \multicolumn{3}{l}{ Platelet count (platelets $\left.\times 10^{9} / l\right)$} \\
\cline { 2 - 4 } & $\begin{array}{l}\text { Whole } \\
\text { blood }\end{array}$ & $\begin{array}{l}\text { Platelet rich } \\
\text { plasma }\end{array}$ & $\begin{array}{l}\text { Adjusted } \\
\text { platelet rich } \\
\text { plasma }\end{array}$ \\
\hline $\begin{array}{llll}\text { Systemic sclerosis } \\
\text { Normal controls }\end{array}$ & $\begin{array}{l}192(50)^{*} \\
145(50)\end{array}$ & $\begin{array}{l}397(93) \mathrm{NS} \\
411(113)\end{array}$ & $\begin{array}{l}250(1) \mathrm{NS} \\
250(1)\end{array}$
\end{tabular}

${ }^{*} \mathrm{p}<0.05$, Mann-Whitney test.

in whole blood in both groups $(p<0.05$, Wilcoxon's signed rank pair test). The platelet distribution width (table 3 ) was significantly lower in platelet rich plasma than in whole blood in the control group ( $p<0.05$, Wilcoxon's signed rank pair test), but not in the patient group. No significant difference was found in mean platelet volume or platelet distribution width between the patient group and the control group. The platelet count (table 4) was significantly lower in whole blood obtained from patients with systemic sclerosis than in control blood samples $(p<0.05$, Mann-Whitney test). None of the patients or control subjects had a platelet count which would be considered abnormal.

AGGREGATION INDUCED BY PLATELET ACTIVATING FACTOR AND THE EFFECT OF BN52063

The effects of platelet activating factor and BN52063 were determined on platelet rich plasma prepared from blood samples taken from 12 female patients with systemic sclerosis (mean age 53 years, range 38-68) and 12 female control subjects (mean age 46 years, range 25-60) (figs 1 and 2). Dose dependent platelet aggregation was seen in all samples in response to $0.02-1.25 \mu \mathrm{M}$ platelet activating factor. There was no significant difference in response to this factor between the control and patient groups, either in rate of primary aggregation or maximum percentage aggregation (analysis of variance).

The effect of BN52063 on aggregation induced by platelet activating factor was analysed by repeated measures analysis of variance. The results were similar for both slope and maximum percentage aggregation. In each case there was no difference between the two groups. There was a dependence of slope and maximum percentage aggregation on both platelet activating factor and BN52063 concentrations $(\mathrm{p}<0.001)$; this dependence was the same for both groups. There was also a platelet activating 




Figure 1 Effect of BN52063 on the rate of primary aggregation induced by platelet activating factor in controls $(-)$ and patients with systemic sclerosis (- - -). Platelet rich plasma was pretreated with BN52063 at O(A), 1 molll $(\diamond), 10 \mu \mathrm{molll}(\mathrm{O})$, and $100 \mathrm{\mu molll}(\mathrm{Q})$.

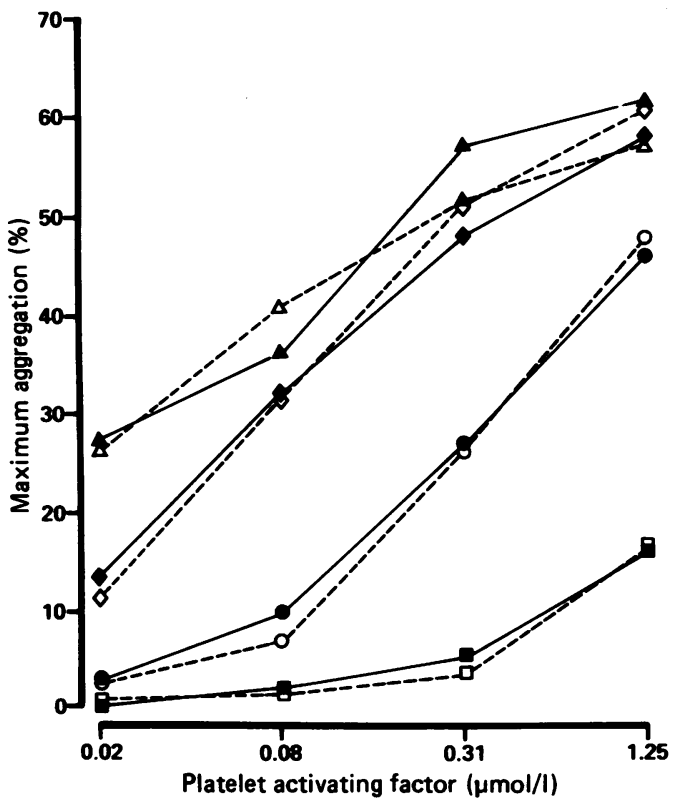

Figure 2 Effect of BN52063 on the maximum percentage aggregation induced by platelet actioating factor in controls $(-)$ and patients with systemic sclerosis (- - ). Platelet rich plasma was pretreated with BN52063 at $\mathrm{O}(\mathrm{\Delta})$,

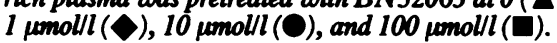

factor-BN52063 interaction-that is, the dependence on platelet activating factor varied with BN52063 concentration.

ADP INDUCED AGGREGATION AND THE EFFECT OF BN52063

Blood samples were obtained from 18 patients with systemic sclerosis (mean age 55 years, range 37-73) and 17 control subjects (mean age 43 years, range 24-68). Figures 3 and 4 show the response of platelet rich plasma to $0 \cdot 31-50$ $\mu M$ ADP. Dose dependent, ADP induced aggregation was seen in all samples. There was



Figure $3 A D P$ induced aggregation in controls $(-)$ and patients with systemic sclerosis (- - -) expressed as the rate of primary aggregation. Points represent mean (SD) for 17 subjects (control group) or 18 subjects (patient group).

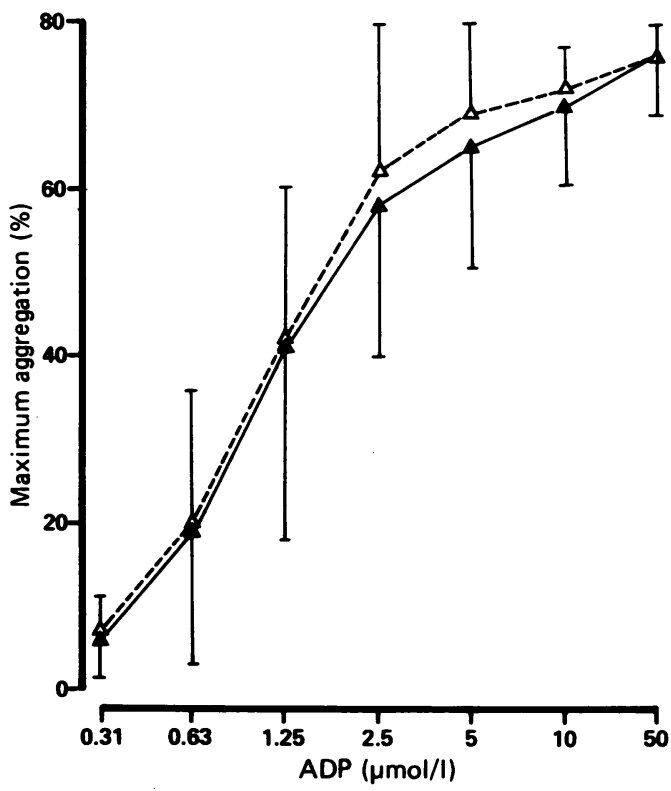

Figure 4 ADP induced aggregation in controls $(-)$ and patients with systemic sclerosis (- - -) expressed as the maximum percentage aggregation. Points represent mean (SD) for 17 subjects (control group) or 18 subjects (patient group).

no significant difference in response to ADP between the patient and control groups, either in rate of primary aggregation or maximum percentage aggregation (analysis of variance). Table 5 shows the effect of $1-100 \mu \mathrm{M}$ BN52063 on ADP induced aggregation in three control samples. BN52063 had no inhibitory action on ADP induced aggregation in these samples.

COLLAGEN INDUCED AGGREGATION

The response of platelet rich plasma obtained from 12 patients with systemic sclerosis (mean age 54 years, range 37-72) and 18 control 
Table 5 Effect of BN52063 on ADP induced aggregation in three control platelet rich plasma samples. Results are given as the rate of primary aggregation (expressed as slope at the steepest part of the curve) and maximum percentage aggregation $($ mean $(S D))$

\begin{tabular}{|c|c|c|c|c|c|}
\hline \multirow[t]{2}{*}{$\begin{array}{l}A D P \\
(\mu \mathrm{mol} / \mathrm{l})\end{array}$} & \multirow[t]{2}{*}{$\begin{array}{l}\text { BN52063 } \\
\text { (umolll })\end{array}$} & \multicolumn{2}{|c|}{$\begin{array}{l}\text { Rate of primary } \\
\text { aggregation }\end{array}$} & \multicolumn{2}{|c|}{$\begin{array}{l}\text { Maximum percentage } \\
\text { aggregation }\end{array}$} \\
\hline & & Mean & $S D$ & Mean & $S D$ \\
\hline 0.63 & $\begin{array}{r}0 \\
1 \\
10 \\
100\end{array}$ & $\begin{array}{l}16 \\
16 \\
18 \\
17\end{array}$ & $\begin{array}{l}3 \\
3 \\
5 \\
5\end{array}$ & $\begin{array}{l}14 \\
13 \\
13 \\
17\end{array}$ & $\begin{array}{l}4 \\
3 \\
2 \\
8\end{array}$ \\
\hline $2 \cdot 50$ & $\begin{array}{r}0 \\
1 \\
10 \\
100\end{array}$ & $\begin{array}{l}34 \\
35 \\
32 \\
34\end{array}$ & $\begin{array}{l}2 \\
1 \\
2 \\
3\end{array}$ & $\begin{array}{l}66 \\
70 \\
67 \\
67\end{array}$ & $\begin{array}{r}12 \\
6 \\
9 \\
9\end{array}$ \\
\hline $10 \cdot 00$ & $\begin{array}{r}0 \\
1 \\
10 \\
100\end{array}$ & $\begin{array}{l}44 \\
40 \\
42 \\
42\end{array}$ & $\begin{array}{l}5 \\
3 \\
1 \\
4\end{array}$ & $\begin{array}{l}79 \\
73 \\
79 \\
76\end{array}$ & $\begin{array}{r}9 \\
11 \\
6 \\
7\end{array}$ \\
\hline
\end{tabular}

Table 6 Collagen induced platelet aggregation in 12 patients with systemic sclerosis and in 18 control subjects. Results are expressed as mean (SD)

\begin{tabular}{llll}
\hline & $\begin{array}{l}\text { Lage phase } \\
\text { (min) }\end{array}$ & $\begin{array}{l}\text { Rate of } \\
\text { primary } \\
\text { aggregation }\end{array}$ & $\begin{array}{l}\text { Maximum } \\
\text { percentage } \\
\text { aggregation }\end{array}$ \\
\hline Systemic sclerosis & $1 \cdot 3(0 \cdot 7)$ & $39(8)$ & $73(12)$ \\
Normal controls & $1 \cdot 2(0 \cdot 7)$ & $42(10)$ & $68(13)$ \\
\hline
\end{tabular}

subjects (mean age 40 years, range 20-59) to $0.19 \mathrm{mg} / \mathrm{ml}$ collagen was determined. A lag phase followed by a single wave of irreversible aggregation was seen in each sample of platelet rich plasma (table 6). There was no significant difference between the two groups in lag phase, rate of primary aggregation, or maximum percentage aggregation (Mann-Whitney test).

\section{Discussion}

Several studies have been carried out to investigate in vitro platelet aggregation in systemic sclerosis. Most of these used samples of platelet rich plasma. Increased platelet aggregability in systemic sclerosis has been reported in response to some agents, including $\mathrm{ADP}^{3}$ and arachidonic acid. ${ }^{5}$ Friedhoff $e t$ al reported increased in vitro platelet aggregation in patients with early systemic sclerosis after stimulation with 5-hydroxytryptamine, ADP, adrenaline, and collagen. ${ }^{4}$ In contrast, normal aggregation in response to adrenaline and collagen has been reported. ${ }^{3}$ In studies with whole blood Goodfield et al reported increased collagen induced platelet aggregation in systemic sclerosis, but the responses to adrenaline and ADP' were normal. ${ }^{6}$ In our studies, with ADP, collagen, and platelet activating factor as agonists, platelet aggregation in systemic sclerosis was found to be normal.

Contradictory reports on platelet aggregation in systemic sclerosis may be due to differences in the methods used in each laboratory. The technique must be standardised as many factors influence in vitro platelet aggregation, including temperature, platelet count, type and concentration of anticoagulant, bench age of platelet rich plasma, white cell count, $\mathrm{pH}$, and duration of incubation. Other factors which are harder to control may also be important-for example, the relative degree of previous in vivo activation, the presence of other agonists-for example, ADP, physical exercise, mental stress, plasma lipid concentrations and composition, and plasma fibrinogen concentrations.

A normal response of platelets from patients with systemic sclerosis to some aggregating agents was found in the studies reported here and in those of Meyerhoff $e t \boldsymbol{a l}^{3}$ and Goodfield et al. ${ }^{6}$ Normal platelet activation might have been seen because a subpopulation of hyperactive platelets had been consumed in vivo leaving only less reactive platelets in the circulation. The active platelets might have been 'exhausted' by being used in vivo during activation by exposed subendothelium at sites of endothelial damage. After aggregation and disaggregation the platelets would be returned to the circulation refractory to further stimulation by the same agonist. Alternatively, any hyperactive platelets might have been lost during preparation of the platelet rich plasma.

Comparison of the mean platelet volume and platelet distribution width in whole blood and platelet rich plasma supports this hypothesis as it was found that some of the larger, denser platelets were lost during centrifugation. Karpatkin and Charmatz reported that heavy, dense platelets are metabolically and functionally more active. ${ }^{8}$

Possibly, platelet hyperactivity occurs only at one particular stage of the disease process. The studies reported here were carried out mainly on patients with disease duration of more than five years. If platelet hyperactivity only occurs in patients with early disease, as reported by Friedhoff $e t a l,{ }^{4}$ it would not be seen in this patient group.

The results reported here provide no evidence in support of the hypothesis that platelet hyperactivity is a fundamental feature of systemic sclerosis. Disappointing results which have been obtained with antiplatelet drugs ${ }^{9}$ might have been because either platelet activation has less importance than has been previously suggested in systemic sclerosis or because complete inhibition of platelet activation has not yet been achieved. It has been shown that at concentrations of $1-100 \mu \mathrm{mol} / 1 \mathrm{BN} 52063$ is a dose dependent, competitive antagonist of platelet aggregation induced in vitro by platelet activating factor, and it has no effect on ADP induced aggregation. BN52063 was the first platelet activating factor antagonist shown to be active in man. ${ }^{10}$ Subsequent clinical trials have shown BN52063 to be effective in inflammatory disorders, including asthma ${ }^{11} 12$ and systemic mastocytosis. ${ }^{13}$ Although normal platelet sensitivity to platelet activating factor was seen in systemic sclerosis, it is possible that platelet activation might be caused by hyperproduction of platelet activating factor occurring at some stage of the disease. If this is the case, a specific platelet activating factor antagonist may be beneficial in counteracting the effects of the large quantities of platelet activating factor produced. Platelet activating factor is considered to be an important mediator of inflammation ${ }^{14}$ and may have a role in the pathology of systemic sclerosis. Platelet activating factor is only one component of a complex, integrated system, 
however, and therefore a more successful therapeutic regimen would probably consist of a combination of drugs.

1 LeRoy E C. The vascular defect in scleroderma (systemic sclerosis). Acta Medica Scandinavica 1987; 715 (suppl):

2 Mustard J F, Kinlough-Rathbone R L, Packham M A. Platelet activation-an overview. Agents Actions 1987; 21: 23-6.

3 Meyerhoff J, Dorsch C A. Platelet aggregation in systemic sclerosis (SS). Arthritis Rhewm 1981; 24 (suppl): 85 .

4 Friedhoff L T, Seibold J R, Kim H C, Simester K S. Serotonin induced platelet aggregation in systemic sclerosis. Clin Exp Rhesumatol 1984; 2: 119-23.

5 Reilly I A G, Roy L, Fitzgerald G A. Biosynthesis of thromboxane in patients with systemic sclerosis and Raynaud's phenomenon. BMF 1986; 292: 1037-9.

6 Goodfield M J D, Orchard M A, Rowell N R. Increased platelet sensitivity to collagen-induced aggregation in whole blood in patients with systemic sclerosis. Clin Exp Rheumatol 1988; 6: 285-8.

7 Garrow J S. Treat obesisy seriously. Edinburgh: Churchill Livingstone, 1981.
8 Karpatkin S, Charmatz A. Heterogeneity of human platelets. I. Metabolic and kinetic evidence of young and old platelets. II. Functional evidence suggestive of young and old platelets. f Clin Invest 1969; 48: 1073-83.

9 Beckett V L, Conn D L, Foster V, et al. Trial of plateletinhibiting drug in scleroderma. Double-blind study with aspirin and dipyridamole. Arthritis Rhewn 1984; 27: $1137-43$.

10 Guinot $\mathrm{Ph}$, Braquet $\mathrm{P}$, Duchier J, Cournot A. Inhibition of PAF-induced wheal and flare reaction in man by a specific PAF-induced wheal and flare reaction in man by

11 Guinot $\mathrm{Ph}$, Brambilla C, Duchier J, Braquet $\mathrm{P}$, Bonvoisin B Cournot A. Effect of BN52063, a specific PAF-antagonist, on bronchial provocation test to allergans in asthmatic patients. A preliminary study. Prostaglandins 1987; 34 723-31.

12 Wilkens J H, Wilkens $H$, Uffmann J, Bovers J, Fabel $H$ Frolich J C. Effects of a ginkgolide preparation (BN52063) on platelet activation during exercise-induced asthma in man. Eur $f$ Clin Pharmacol (in press).

13 Guinot $\mathrm{Ph}$, Summerhayes S, Berdah L, Duchier J, Revillaud $R$ J. Treatment of adult systemic mastocytosis with a PAF acether antagonist, BN52063. Lancet 1988; ii: 114 .

14 Lagente V, Fortes Z B. Role of PAF-acether in the vascular events of inflammation. Prog Biochem Pharmacol 1988; 22: 149-55. 